\title{
Preoperative staging of lung cancer: accuracy of computed tomography versus mediastinoscopy
}

\author{
P GOLDSTRAW, M KURZER, D EDWARDS
}

From the Departments of Thoracic Surgery and Radiology, University College Hospital, London

ABSTRACT Forty-four patients coming to surgery for carcinoma of the bronchus underwent preoperative staging of the mediastinum by computed tomography (CT scanning) and surgical exploration of the mediastinum by cervical mediastinoscopy or left anterior mediastinotomy or both. Where mediastinal nodes were affected the sensitivity and specificity of computed tomography was inferior to that of mediastinoscopy (57\% and $85 \%$ versus $71 \%$ and $100 \%$ ). The sensitivity of computed tomography in predicting mediastinal invasion was superior to that of mediastinoscopy $(77 \% \vee 46 \%)$, especially in the case of lower-lobe tumours $(67 \% v 17 \%)$. Mediastinoscopy had the considerable advantage of $100 \%$ specificity. In the assessment of hilar lymphadenopathy computed tomography had a sensitivity of $38 \%$ and a specificity of $64 \%$. In cases where computed tomography showed a normal mediastinum or enlargement of the hilar glands only, mediastinal exploration conferred no additional information and could have been omitted. A computed tomography scan showing mediastinal abnormality is an indication for mediastinoscopy and not a contraindication to surgery. In 23 patients computed tomography showed some abnormality of the mediastinum, confirmed at mediastinoscopy in 12 cases. The remaining 11 patients underwent thoracotomy, resection being carried out in nine. Postsurgical staging showed that six of these tumours were $\mathrm{N}_{0}$ lesions without invasion; in two further $\mathrm{N}_{0}$ cases there was a minor degree of mediastinal invasion which did not prevent resection, and the remaining tumour was $N_{1}$ without invasion.

Surgical exploration of the mediastinum using cervical mediastinoscopy, supplemented in left upper-lobe tumours by left anterior mediastinotomy, has become an established staging procedure before thoracotomy. Some dissatisfaction with this invasive procedure, however, and the increasing use of computed tomography for visualising the mediastinum led us to carry out a prospective study to evaluate the accuracy of these two techniques in the preoperative staging of lung cancer.

\section{Patients and methods}

Forty-four patients-30 men and 14 women aged 5070 years (mean 62.5 years)-with known or presumptive bronchogenic carcinoma, referred for surgery to the thoracic unit at University College Hospital, were studied before operation with the EMI scanner (whole-body scanner model 5005). Cuts $13 \mathrm{~mm}$ thick were taken at $2 \mathrm{~cm}$ intervals throughout

Address for reprint requests: Mr P Goldstraw, Department of Thoracic Surgery, University College Hospital, London WC1. the chest and upper abdomen. Mediastinal invasion was deemed present if the tumour opacity could not be separated from the mediastinum, and any opacities within the mediastinum greater than $1.5 \mathrm{~cm}$ in diameter were considered pathological glands. The computed tomography findings were known to the surgeon, but they did not influence management. All patients underwent surgical exploration of the mediastinum before thoracotomy. Tumours of the left upper lobe were assessed by left anterior mediastinoscopy, at first in addition to mediastinoscopy but latterly on its own. All other patients underwent cervical mediastinoscopy.

Tissue diagnosis was provided by sputum cytology in seven cases, by percutaneous needle biopsy of the tumour in 10 , and by bronchoscopic biopsy in 18 . In nine cases diagnosis was established only at operation from tissue obtained at mediastinoscopy or $\stackrel{\mathscr{D}}{?}$ thoracotomy. Table 1 shows the distribution of cell 7 types. Patients were considered for surgery if there was no clinical, biochemical, or radiological evidence of dissemination. Radioisotope scans of liver. bone, and brain were performed only when there was 
Table 1 Distribution of cell types in the tumours

\begin{tabular}{|c|c|c|c|c|c|c|}
\hline \multirow[t]{2}{*}{ Histological type } & \multicolumn{2}{|c|}{ Upper lobe } & \multirow[t]{2}{*}{ Middle lobe } & \multicolumn{2}{|c|}{ Lower lobe } & \multirow[t]{2}{*}{ Total } \\
\hline & Left & Right & & Left & Right & \\
\hline $\begin{array}{l}\text { Squamous } \\
\text { Adenocarcinoma } \\
\text { Alveolar cell } \\
\text { Large-cell undifferentiated } \\
\text { Small-cell undifferentiated (oat cell) }\end{array}$ & $\begin{array}{r}13 \\
1 \\
0 \\
0 \\
0\end{array}$ & $\begin{array}{l}5 \\
2 \\
0 \\
0 \\
0\end{array}$ & $\begin{array}{l}2 \\
1 \\
1 \\
0 \\
0\end{array}$ & $\begin{array}{l}5 \\
3 \\
0 \\
0 \\
1\end{array}$ & $\begin{array}{l}8 \\
1 \\
0 \\
1 \\
0\end{array}$ & $\begin{array}{r}33 \\
8 \\
1 \\
1 \\
1\end{array}$ \\
\hline Total & 14 & 7 & 4 & 9 & 10 & 44 \\
\hline
\end{tabular}

Table 2 Distribution of tumours and eventual outcome

\begin{tabular}{lllll}
\hline Surgery & Lower lobe & Middle lobe & Upper lobe & Total \\
\hline No thoracotomy & 2 & 2 & 7 & 11 \\
Thoracotomy alone & 2 & 0 & 1 & 3 \\
Lobectomy & 8 & 1 & 9 & 18 \\
Pneumonectomy & 7 & 1 & 4 & 12 \\
Total & 19 & 4 & 21 & 44 \\
\hline
\end{tabular}

weight loss of more than $3 \mathrm{~kg}$ or abnormal results in liver function tests or serum calcium estimation.

Preoperative mediastinal exploration was performed by cervical mediastinoscopy in 36 patients, by left anterior mediastinotomy in four, and by both approaches in four. Biopsy material taken during these procedures was sent for frozen-section analysis before thoracotomy was performed. Patients with nodal metastases or evidence of mediastinal invasion were considered unsuitable for thoracotomy. The patients thus fell into three groups: 11 underwent mediastinal exploration and as the result was positive they were considered unsuitable for thoracotomy; three underwent mediastinal exploration and exploratory thoracotomy but resection was not undertaken; and 30 underwent mediastinal exploration followed by thoracotomy and pulmonary resection, 18 patients undergoing lobectomy and 12 pneumonectomy. The sites of the primary lesions and surgical procedures undertaken are shown in table 2 . Nodes taken at mediastinal exploration and thoracotomy were carefully labelled to facilitate later staging.

After surgery the prediction derived from computed tomography was correlated with the operative findings and the histological details of resected specimens. The ability of computed tomography to predict the presence of spread to mediastinal nodes was compared with the results of mediastinal exploration. True-positive and falsepositive predictions and true-negative and falsenegative predictions were recorded for each test, and it was then possible to determine the sensitivity (percentage of cases correctly identified as positive) and the specificity (percentage of cases correctly identified as negative). These figures were considered both for the whole group and for the subgroups with the upper lobe and the lower lobe affected. For the sake of anatomical symmetry the middle lobe was included with the upper lobe subset on the right.

A similar comparison was made for the ability of computed tomography and mediastinal exploration to predict the presence of mediastinal invasion; again the figures were considered both for the whole group and for the upper-lobe and the lower-lobe subsets.

\section{Results}

The computed tomography predictions and findings at mediastinal exploration and thoracotomy are shown in table 3 alongside the postsurgical staging of the mediastinum.

\section{$C T$ scans predicting normal mediastinum and hilum}

There were 13 cases in which computed tomography was reported as showing a normal hilum and mediastinum. Mediastinoscopy gave negative results in all these cases. The tumours all proved resectable, although in one case the presence of multiple adenocarcinomas (not seen on the CT scan) suggested secondaries and no resection was undertaken. Of the other 12 tumours, nine were resected by lobectomy or bilobectomy and three by pneumonectomy. The postsurgical staging of these cases is shown in table 3 . Eight of these tumours were $N_{0}$ but in one case invasion was present, which had been missed by both staging techniques. In addition, there were three $N_{1}$ and one $\mathrm{N}_{2}$. 
Table 3 Correlation of findings from different staging procedures

\begin{tabular}{|c|c|c|c|c|c|c|}
\hline$C T$ scan prediction & No & $\begin{array}{l}\text { Findings at } \\
\text { mediastinal } \\
\text { exploration }\end{array}$ & No & $\begin{array}{l}\text { Findings at } \\
\text { thoracotomy }\end{array}$ & No & Postsurgical staging \\
\hline Normal mediastinum and hilum & 13 & Negative & 13 & $\begin{array}{l}\text { Resectable } \\
\text { Not resected }\end{array}$ & $\begin{array}{r}12 \\
1\end{array}$ & $\begin{array}{l}8 \mathrm{~N}_{0}(1 \text { with invasion }), 3 \mathrm{~N}_{1}, 1 \mathrm{~N}_{2} \\
\text { Multiple deposits }\end{array}$ \\
\hline $\begin{array}{l}\text { Normal mediastinum, abnormal hilum } \\
\text { Abnormal mediastinum }\end{array}$ & 8 & Negative & 8 & Resectable & 8 & $3 \mathrm{~N}_{0}, 3 \mathrm{~N}_{1}, 2 \mathrm{~N}_{2}$. No invasion \\
\hline Overall & 23 & $\begin{array}{l}\text { Positive } \\
\text { Negative }\end{array}$ & 12 & $\begin{array}{l}\text { Resectable } \\
\text { No thoracotomy } \\
\text { Resectable } \\
\text { Not resected }\end{array}$ & $\begin{array}{r}1 \\
11 \\
9 \\
2\end{array}$ & $\begin{array}{l}\mathrm{N}_{2}, 6 \mathrm{~T}_{3} \text { (known palliative resection) } \\
9 \mathrm{~N}_{2}, 6 \mathrm{~T}_{3} \\
8 \mathrm{~N}_{0}(2 \text { with invasion }), 1 \mathrm{~N}_{1} \\
2 \mathrm{~T}_{3}, 1 \mathrm{~N}_{2}\end{array}$ \\
\hline Glands affected & 12 & Confirmed glands & 8 & $\begin{array}{l}\text { Resectable } \\
\text { No thoracotomy }\end{array}$ & $\begin{array}{l}1 \\
7\end{array}$ & $\begin{array}{l}\mathrm{N}_{2}, T_{3} \text { (known palliative resection) } \\
6 \mathrm{~N}_{2}, 4 \mathrm{~T}_{3}\end{array}$ \\
\hline Invasion & 18 & $\begin{array}{l}\text { Negative } \\
\text { Confirmed invasion }\end{array}$ & $\begin{array}{l}4 \\
6\end{array}$ & $\begin{array}{l}\text { Resectable } \\
\text { No thoracotomy }\end{array}$ & $\begin{array}{l}4 \\
6\end{array}$ & $\begin{array}{l}3 \mathrm{~N}_{0}(1 \text { with invasion }), 1 \mathrm{~N}_{1} \\
6 \mathrm{~T}_{3}, 4 \mathrm{~N}_{2}\end{array}$ \\
\hline & & $\begin{array}{l}\text { Glands, no invasion } \\
\text { Negative }\end{array}$ & $\begin{array}{l}4 \\
8\end{array}$ & $\begin{array}{l}\text { No thoracotomy } \\
\text { Resectable } \\
\text { Not resected }\end{array}$ & $\begin{array}{l}4 \\
6 \\
2\end{array}$ & $\begin{array}{l}4 \mathrm{~N}_{2} \\
6 \mathrm{~N}_{0}(2 \text { with invasion }) \\
2 \mathrm{~T}_{3}, 1 \mathrm{~N}\end{array}$ \\
\hline
\end{tabular}

Table 4 Sensitivity and specificity of computed tomography and mediastinal exploration in predicting spread of tumour to mediastinal glands

\begin{tabular}{llllll}
\hline & Site of tumour & No & $\begin{array}{l}\text { Sensitivity: } \\
\text { No }(\%) \text { of positive cases identified }\end{array}$ & $\begin{array}{l}\text { Specificity: } \\
\text { No (\%) of negative cases identified }\end{array}$ \\
\hline Computed tomography scan & Upper lobe & 23 & $5 / 9$ & $(56)$ & $11 / 14(79)$ \\
& Lower lobe & 18 & $3 / 5$ & $(60)$ & $12 / 13(92)$ \\
& All* & 41 & $8 / 14$ & $(57)$ & $23 / 27(86)$ \\
Mediastinal exploration & Upper lobe & 23 & $7 / 9$ & $(78)$ & $14 / 14(100)$ \\
& Lower lobe & 17 & $3 / 5$ & $(60)$ & $12 / 12(100)$ \\
& All ${ }^{\dagger}$ & 40 & $10 / 14(71)$ & $26 / 26(100)$ & \\
\hline
\end{tabular}

*Excludes two cases where invasion at mediastinal exploration and one case where invasion at thoracotomy prevented proper exclusion of spread to mediastinal glands.

†Excludes in addition one case where findings at mediastinal exploration were not available for review.

CT scans predicting normal mediastinum and abnormal hilum

There were eight cases in which the only abnormality on the CT scan was enlargement of hilar glands (four were upper-lobe tumours and four lower-lobe). Mediastinoscopy gave negative results in all eight cases and all these tumours proved resectable - three by lobectomy and five by pneumonectomy. Subsequent histological examination showed three tumours to be $\mathrm{N}_{0}$, three $\mathrm{N}_{1}$, and two $\mathrm{N}_{2}$ (table 3).

In our study the sensitivity of computed tomography in detecting spread to hilar glands was $38 \%$ and the specificity $64 \%$.

\section{Abnormal CT scans of the mediastinum}

Computed tomography of the mediastinum showed abnormalities interpreted as mediastinal invasion or spread to the glands or both in 23 cases (table 3). In 12 cases an abnormality was confirmed at mediastinoscopy, though in one case a palliative pneumonectomy was later undertaken. Of the remaining 11 tumours, two proved to be unresectable because of the $\underset{x}{\stackrel{2}{\nu}}$ extensive invasion predicted from the CT scan and $\frac{0}{5}$ the other nine were resectable. Six of these tumours were $\mathrm{N}_{0}$ lesions without invasion, two others were $\mathrm{N}_{0}$ ᄋे lesions with invasion, and one was an $N_{1}$ lesion $₹$ without invasion.

\section{CT scans predicting spread to mediastinal glands}

The accuracy with which computed tomography indicated tumour spread to mediastinal glands is $\sigma$ compared with the accuracy of mediastinal $N$ exploration in table 4 . Three cases were excluded $\underset{\omega}{N}$ from this part of the study since invasion at $\bar{O}$ mediastinoscopy in two cases and at thoracotomy in 0 one case prevented a thorough examination of $\stackrel{\mathbb{D}}{\overparen{D}}$ mediastinal glands, which may or may not have been $\stackrel{\mathcal{P}}{+}$ affected. In addition, in one patient the detailed 0 mediastinoscopy report could not be reviewed and hence this case was excluded from the results of mediastinoscopy.

Mediastinoscopy proved more sensitive than 
Table 5 Sensitivity and specificity of computed tomography and mediastinal exploration in predicting mediastinal invasion

\begin{tabular}{llllll}
\hline & Site of tumour & No & $\begin{array}{l}\text { Sensitivity: } \\
\text { No }(\%) \text { of positive cases identified }\end{array}$ & $\begin{array}{l}\text { Specificity: } \\
\text { No (\%) of negative cases identified }\end{array}$ \\
\hline Computed tomography & Upper lobe & 21 & $6 / 7(86)$ & $11 / 14(79)$ \\
& Lower lobe & 18 & $4 / 6(67)$ & $11 / 12(92)$ \\
& All* & 39 & $10 / 13(77)$ & $22 / 26(85)$ \\
Mediastinal exploration & Upper lobe & 21 & $5 / 7(71)$ & $14 / 14(100)$ \\
& Lower lobe & 17 & $1 / 6(17)$ & $11 / 11(100)$ \\
& All $\dagger$ & 38 & $6 / 13(46)$ & $25 / 25(100)$ \\
\hline
\end{tabular}

*Excludes five cases where spread of the glands at mediastinal exploration precluded thoracotomy and there was therefore no proper confirmation of mediastinal invasion.

†Excludes in addition one case where details of mediastinal exploration were not available for review.

computed tomography at indicating spread to mediastinal nodes $(71 \% \vee 57 \%)$ because of its considerable superiority with upper-lobe tumours $(78 \% v 56 \%)$. For lower-lobe tumours the two techniques were equally sensitive $(60 \%)$. Similarly, mediastinoscopy was more specific than computed tomography $(100 \% v 86 \%)$ and again the difference was greater for upper-lobe tumours $(100 \% v 79 \%)$ than lower-lobe tumours $(100 \% \vee 92 \%)$. Combining the two techniques was of no value since the sensitivity was no greater than that of the more accurate investigation (mediastinoscopy) while the specificity fell to that of the less accurate one (computed tomography).

There were four cases in which computed tomography predicted the presence of affected mediastinal glands and where mediastinoscopy gave negative results (table 3 ). All four tumours proved resectable, three by lobectomy and one by pneumonectomy; three were $\mathrm{N}_{0}$ and one $\mathrm{N}_{1}$. In three of these cases, however, the tumour was in the upper lobe.

\section{CT scans predicting mediastinal invasion}

The sensitivity and specificity of assessment of mediastinal invasion by computed tomography and mediastinal exploration is shown in table 5. The results exclude five cases in which glands were found to be affected at mediastinoscopy and therefore thoracotomy was not performed, which left the possibility that mediastinal invasion was present beyond the reach of the mediastinoscope.

Computed tomography was more sensitive than mediastinoscopy $(77 \% v 46 \%)$-particularly in the case of lower-lobe tumours $(67 \% \vee 17 \%)$, where the performance of mediastinoscopy would be expected to be poor. Computed tomography was also more sensitive, however, for upper-lobe tumours $(86 \% v$ $71 \%$ ). Mediastinoscopy retained the considerable advantage of $100 \%$ specificity, giving no falsepositive results. Again, combining the techniques was unsatisfactory since it did not give a greater sensitivity than the more sensitive investigation-in this case computed tomography - and it reduced specificity to the level of the less sensitive one-that is, computed tomography.

There were eight cases in which computed tomography predicted the presence of mediastinal invasion but in which the findings at mediastinoscopy were normal. Six proved resectable and even in the case of lower-lobe tumours half were resectable (table 3). Of the resectable lesions, all were $\mathrm{N}_{0}$ but in two a minor degree of invasion was present which did not prevent resection.

Stage 3 tumours where findings at mediastinoscopy were normal

In 10 cases thoracotomy was undertaken after mediastinal exploration had given negative results, where it might be argued that surgery was inappropriate. These cases could be considered as our failures of assessment and they represent the false-negative results of mediastinal exploration. The failures fall into four groups:

(1) Two lower-lobe tumours were unresectable at thoracotomy because of invasion into the mediastinum beyond the reach of the mediastinoscope. This invasion had been predicted from the CT scans. (2) One patient was found to have multiple deposits of adenocarcinoma. These additional deposits had been missed on the CT scan. (3) There were four $\mathrm{N}_{0}$ lesions which were resected despite local mediastinal invasion. The invasion was noted on the CT scan in two cases, but missed in two others. In all four cases (two upperlobe and two lower-lobe tumours), the invasion was beyond the reach of the mediastinoscope. (4) Three patients underwent resection and their tumours were retrospectively staged as $\mathrm{N}_{2}$. In the case of one left upper-lobe tumour assessment was made inappropriately via cervical mediastinoscopy and an affected gland outside the aortic arch was found at thoracotomy. A second left upper-lobe lesion was assessed via a left anterior mediastinotomy and an affected gland in the subaortic fossa was wrongly 
interpreted as atheroma in the aortic arch. The third case was a lower-lobe tumour with microscopic deposits in the main carinal glands. In none of these three cases did computed tomography detect that nodes were affected.

In the case of four tumours (two resectable) computed tomography accurately predicted the abnormality, but in the other six cases (five resected) the abnormality escaped detection at mediastinoscopy and computed tomography.

\section{Discussion}

Lung cancers affecting the mediastinum are stage III tumours by virtue of mediastinal invasion $\left(\mathrm{T}_{3}\right)$ or spread to mediastinal lymh nodes $\left(\mathrm{N}_{2}\right)$. While surgery may still be reasonable in a highly selected subgroup of patients with $\mathrm{N}_{2}$ lesions, in general patients with stage III tumours are acknowledged to have a much worse prognosis and hence the morbidity and mortality of surgery becomes unacceptable. An assessment of the mediastinum is made by all surgeons before surgery with various techniques, including bronchoscopy, mediastinal tomography, and barium-swallow examination to detect displacement of the oesophagus. Surgical assessment of the mediastinum using mediastinoscopy supplemented by anterior mediastinotomy in selected cases avoids thoracotomy in those cases in which the tumour proves to be unresectable and those in which resection is undesirable.' Mediastinoscopy has not become universally used since it is not without risk ${ }^{1-4}$ and allows only a limited evaluation of the mediastinum. There are lymph-node groups within the superior mediastinum which are inaccessible to cervical mediastinoscopy, ' although where these are likely to be affected, as with left upper-lobe tumours, anterior mediastinotomy may increase sensitivity. ${ }^{5}$ Nodal metastases at the carina and beyond, or invasion of the lower mediastinum, cannot be assessed.

If mediastinal exploration is performed immediately before thoracotomy, facilities are necessary for making frozen sections rapidly available; if it is undertaken as an interval procedure resulting inflammation may make assessment of the mediastinum at thoracotomy more difficult. There is also continued uncertainty about the importance of microscopic intracapsular deposits in ipsilateral, low paratracheal glands with right-sided squamous tumours. ${ }^{6}$

Computed tomography has greatly increased radiographic visualisation of intrathoracic structures and has increasing use in thoracic surgery. Its value in delineating intrathoracic metastases is now well established, ${ }^{7-9}$ and it is useful in outlining the extent of intrathoracic tumours. ${ }^{10}$ It is increasingly used by clinicians to stage lung cancer. ${ }^{11-13}$ Surgeons, however, appreciate that enlarged glands may well be reactive, while glands of normal size may contain microscopic tumour deposits of clinical importance. They are therefore reluctant to base decisions about management on the radiographic delineation of opacities above an arbitrary size.

In our study, where computed tomography showed a normal mediastinum and hilum, mediastinal exploration always gave normal findings. The 13 tumours in this group were all resectable, although resection was not undertaken in one case, where multiple deposits of adenocarcinoma were discovered at thoracotomy. Resection was performed by lobectomy in nine cases $(75 \%)$. Subsequent staging showed 11 cases to be $\mathrm{N}_{0}$ or $\mathrm{N}_{1}$, although a minor degree of invasion was present in one case. One lesion was $\mathrm{N}_{2}$, remaining undiscovered on the CT scan, at mediastinal exploration, and at thoracotomy.

Where computed tomography predicted a normal mediastinum but hilar enlargement, mediastinal exploration again gave normal results and added nothing to the assessment. All eight tumours were resectable, but pneumonectomy was necessary in five patients $(63 \%)$. The finding of a normal mediastinum and hilar enlargement at preoperative computed tomography thus allows the surgeon to dispose with mediastinal exploration and to predict that pneumonectomy is likely to be necessary. These tumours were also more advanced at postsurgical staging; only three were $\mathrm{N}_{0}$, three were $\mathrm{N}_{1}$, and two were $\mathrm{N}_{2}$ lesions. Invasion was not present in any of these cases. Other authors have shown the low accuracy of computed tomography in detecting tumour affecting hilar glands. ${ }^{12}$

A CT scan suggesting affected mediastinal glands or mediastinal invasion is not a contraindication to surgery. Mediastinal exploration was undertaken and in just under half of our cases (11/23) this suggested that the mediastinum was normal. This did not always prove to be the case at thoracotomy, however, and two of the 11 tumours were unresectable. Resection was possible in the other nine cases, eight tumours being $N_{0}$ and one $N_{1}$, although in two cases a minor degree of invasion was present. Clearly mediastinal exploration is not without its faults. In particular, the sensitivity with which it assesses mediastinal invasion in lower-lobe tumours $(17 \%)$ is very poor, but mediastinal invasion found at mediastinoscopy inevitably signals unresectability by the usual criteria, whereas when computed tomography predicts the presence of mediastinal invasion this may in fact be absent and even if present it need not prevent resection. Whether a minor degree of mediastinal invasion makes resection undesirable is not yet 
established. We had four lower-lobe tumours where invasion was predicted by computed tomography but the findings at mediastinal exploration were normal. Two of these tumours proved unresectable because of invasion and the other two were $\mathbf{N}_{0}$ lesions, a minor degree of invasion being confirmed in one case. Mediastinal exploration remains attractive to the surgeon since its $100 \%$ specificity in identifying affected mediastinal glands or invasion means that no one is denied surgery inappropriately.

\section{Conclusions}

(1) Where a CT scan of the mediastinum and hilum is normal, mediastinal exploration may be omitted before thoracotomy.

(2) Where the CT scan shows the mediastinum to be normal but suggests that the hilum is abnormal, mediastinal exploration may similarly be omitted.

(3) Where the CT scan shows an abnormality of the mediastinum, mediastinal exploration should be undertaken; if this gives normal findings thoracotomy is justified.

(4) In units with no CT scanning facilities equally good results may be achieved with the routine preoperative use of mediastinal exploration.

We must counsel care in the translation of these results to other units since the resolution of CT scanners may vary and the manipulation of the software may affect the quality of the image and its interpretation.

We are grateful to the physicians of University College and Whittington Hospitals for referring these cases for surgery. We are also grateful to Mr D Ellis for the illustrations and to Mrs J Field for her secretarial skills.

\section{References}

' Pearson FG. An evaluation of mediastinoscopy in the management of presumably operable bronchial carcinoma. J Thorac Cardiovasc Surg 1968;55:617-25.

${ }^{2}$ Foster ED, Munro DD, Dobell ARC. Mediastinoscopy, a review of anatomical relationships and complications. Ann Thorac Surg 1972;13:273-86.

${ }^{3}$ Gunstensen J, Wade JD. Mediastinoscopy, an analysis of 320 consecutive cases. Br J Surg 1972;59:209-13.

4 Nohl-Oser HC. Mediastinoscopy. Br J Hosp Med 1976;July:33-6.

${ }^{5}$ Bowen TE, Zajtchuk R, Green DC, Brott WH. Value of anterior mediastinotomy in bronchogenic carcinoma of the left upper lobe. J Thorac Cardiovasc Surg 1978;76:269-71.

' Pearson FG, DeLarue NC, Ilves R, Todd TRJ, Cooper JD. Significance of positive superior mediastinal nodes identified at mediastinoscopy in patients with resectable cancer of the lung. $J$ Thorac Cardiovasc Surg 1982;83:1-9.

${ }^{7}$ Muhm JR, Brown LF, Crowe JK. Use of computed tomography in the detection of pulmonary nodules. Proc Mayo Clin 1977;52:345-8.

${ }^{8}$ Jost RG, Sagel SS, Stanley RJ, Levitt RG. Computed tomography of the thorax. Radiology 1978;126:125-36.

${ }^{9}$ Hendry WF, Goldstraw P, Husband JE, Barrett A, McElwain TJ, Peckham MJ. Elective delayed excision of bulky para-aortic lymph node metastases in advanced non-seminoma germ cell tumours of testis. Br J Urol 1981;53:648-53.

${ }^{10}$ Crowe JK, Brown LR, Muhm JR. Computed tomography of the mediastinum. Radiology 1978;128:75-87.

" Underwood GH, Hooper RG, Axelbaum SP, Goodwin DW. Computed tomographic scanning of the thorax in the staging of bronchogenic carcinoma. $N$ Engl J Med 1979;300:777-8.

12 Faling LJ, Pugatch RD, Jung-Legg Y, Daly BDT, Hong WK, Robbins AH, Snider GL. Computed tomographic scanning of the mediastinum in the staging of bronchogenic carcinoma. Am Rev Respir Dis 1981;124:690-5.

${ }^{13}$ Rea HH, Shevland JE, House AJ. Accuracy of computed tomographic scanning in assessment of the mediastinum in bronchial carcinoma. $J$ Thorac Cardiovasc Surg 1981;81:825-9. 